\title{
Assessing Spatial Patterns of Plant Communities at Varying Stages of Succession
}

\author{
Kevin Aagaard1,2*, Gregg Hartvigsen² \\ ${ }^{1}$ Department of Ecology, Evolution, and Natural Resources, Rutgers University, New Brunswick, USA \\ ${ }^{2}$ Department of Biology, SUNY Geneseo, Geneseo, USA \\ Email: aagaard@scarletmail.rutgers.edu
}

Received 31 March 2014; revised 4 May 2014; accepted 12 May 2014

Copyright (C) 2014 by authors and Scientific Research Publishing Inc.

This work is licensed under the Creative Commons Attribution International License (CC BY).

http://creativecommons.org/licenses/by/4.0/

c) (i) Open Access

\begin{abstract}
There is a well known connection between the structural complexity of vegetative stands and ecosystem properties. Developing methods to quantify this structural complexity is an important goal for ecologists. We present an efficient and easily implemented field technique for calculating the shape of forest canopies, and the shape of forest stands as succession occurs, using fractal geometry. Fractal geometry can be used to describe complex, non-Euclidean objects that are common in natural systems. We tested the use of this tool in 22 vegetative and forested plots in Western New York State, USA. We found an asymptotic relationship for fractal dimension (D) as a function of basal area $\left(B A ; r^{2}=0.68\right)$. In a randomization test to investigate the robustness of $D$ to different tree canopy shapes, we found that $D$ was sensitive to canopy shape switching, suggesting that the method is able to differentiate among similar forests comprised of species having different shaped crowns. We conclude that the shape is conserved in vegetative areas as they progress from one stage of succession to the next (range of mean $D: 2.56$ to 2.68 across stages). Furthermore, we conclude that the shape filling properties-i.e., distribution of trunks and limbs in a forested area, measured as mean distance-are also conserved across vegetational chronosequences $(\mathrm{F}=1.3189, \mathrm{df}=8,3, \mathrm{p}=\mathbf{0 . 3 3 4 1})$.
\end{abstract}

\section{Keywords}

Ecological Succession, Fractal Dimension, Vegetational Chronosequence, Crown Shape, Statistical Modeling

\section{Introduction}

It is widely accepted that the structural complexity of a habitat can affect community-level properties like spe-

"Corresponding author. 
cies diversity and richness [1]-[5]. Because of the wide-ranging consequences, it is important to be able to describe this structural complexity in quantifiable ways. This has proven to be a challenging endeavor, however, as familiar mathematical approaches (e.g., Euclidean geometry) have fallen short of providing accurate approximations of biological processes [6] [7]. This has prompted mathematicians and scientists to turn to lesser explored techniques. The product of one such exploration garnered much attention in the three decades since its inception: fractal geometry [6]-[10].

While there are many definitions of varying mathematical accuracy for fractals [11], Mandelbrot [8] [12] initially defined them as objects whose topological dimension is exceeded by their Hausdorff-Besicovitch dimension. For the purposes of this study, we will define a fractal as an object that displays some degree of self-similarity at any scale (for example, Figure 1). Voss ([13]) provides a detailed overview of fractal geometry and the differences between it and Euclidean geometry. Briefly, initial applications for fractal geometry included the classification of coastlines, clouds, mountain range silhouettes, rivers, and a plethora of other natural features, as fractals (or, fractal-like). Fractal geometry has also been used to assess the spatial patterns of communities and forest in satellite images ([6] [11] [14]-[16]); to explain allometric scaling and metabolic processes [17]-[20]; and to examine the growth patterns of individual plants [21].

The defining feature of fractals is that they are scale-independent (or, scale-invariant; [13], see also [22]). This property makes fractal geometry well suited to examine the structural complexity of various communities (e.g., coral reefs, grasslands, kelp forests), and even allows them to be compared to one another. Fractal dimension ( $D$, the shape filling property of an object) has been coupled to the Shannon Index to decipher the relationship between the temporal and spatial complexity of an area [23]. This utility has led to many investigations of the spatial distribution of plants in ecological succession [8] [10] [23]-[27]. For example, in their survey of bird species in various habitats, MacArthur and MacArthur [1] found a correlation between foliage height and forest bird diversity. Their method of analyzing canopy structure, later expanded by MacArthur and Horn [28], involves locating random vertical transects in plots and measuring where these points intercept foliage. Although this method appears to be valuable and flexible e.g. [29], it is tedious and time consuming and thus not practical to implement in the field, especially with limited manpower.

Other methods for estimating and quantifying aspects of canopy structure include leaf area index (LAI), leaf mass per unit area (LMA), and specific leaf mass (SLM, [30] [31]). These metrics only estimate individual-level parameters though, and do not represent community-level measurements. LAI, for one, calculates total leaf area per unit ground area, and provides a useful estimate of leaf surface area for further estimates of parameters such as photosynthesis and productivity measures [32]. This, however, is not an estimate of canopy structure, although higher values do indicate increasing complexity. Shipley and Lechowicz [31] recently introduced a measure for estimating leaf orientation across species, but suggest that metrics for canopy architecture are still needed. At scales smaller than that of forest canopies, there has been much interest in estimating the shape of structures such as leaves and branching patterns [17] [19] [20] [33]-[35], as well as the effect of these shape patterns on dependent species [36]. Missing from these estimates is a rigorous and quantitative measure of canopy shape and associated gaps.

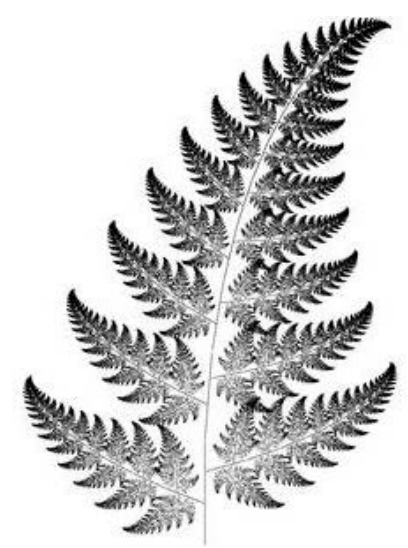

Figure 1. A fern frond is an example of a fractal object. Note how individual branches resemble the larger fern as a whole. 
A major reason for the lack of any canopy shape metric is that there remains so much to understand theoretically regarding these characteristics [7] [37], including how gaps influence recruitment e.g., [38]-[40] and affect associated understory species [41] [42]. Bollinger [43] investigated and reviewed the structure of communities at scales larger than patches and discussed changes in forest structural patterns over time. In terms of a rigorous quantification of these structural patterns, we must employ the unfamiliar approaches mentioned above. Here, we present a new method for quantifying forest canopy shape and gaps using fractal geometry, and show how this can be linked to changes in $D$ over a vegetative chronosequence-a set of differently aged forests assumed to represent a realistic pattern of forest succession.

While this is a novel approach in our system, techniques for determining the fractal dimension of surfaces and digital images have been practiced for years [9] [10]. Applying these techniques in the absence of digitized images (i.e., when using field measurements), however, is difficult. Past methods have included Mandelbrot's perimeter-area method [12], which is incongruous with an analysis taking into account not only length and width, but also height. An effective approach to applying to this three dimensional scenario is known as the box-count method (see Methods; see also [9] [13] [44]). The result of this method is an estimate of $D$, which may become problematic when the smallest scale measured (here we used $0.25 \mathrm{~m}$ ) approaches the size of individuals in the community. In this work, however, the communities measured contained trees greater than a fixed size $(5 \mathrm{~cm}$ diameter at breast height, "DBH") and, therefore, should be amenable to comparison across communities. The plot sizes used to analyze the chronosequences were chosen purposefully to allow for comparison of not only different communities, but communities at different stages of succession.

Despite the high degree of simplification required, approximating a treetop as a simple Euclidean shape works well on a larger scale. This should not be confused with the scale-independent nature of fractals; a fractal at any scale is defined as being self similar, but defining what part of an object has fractal-like behavior does require a scalar dependence. Scalar dependence greatly simplifies using the box-count method to analyze an entire region of vegetation. However, determining the fractal dimension of a region does not produce definitive measures of comparison; a young-growth forest and a meadow may have the same fractal dimension while occupying physical space in very different ways. To account for the gaps that most natural objects have (referred to having lacunarity; [9] [10] [13]) requires another measure, complementary to fractal dimension. The manner in which an object fills space can be measured by the mean distance between points of the object, and this can differentiate objects of similar fractal dimension from one another. The two measurements taken together serve as unique identifiers of an individual plot, and allow for direct comparisons among plots of different stages of succession. We seek to obtain these measurements for a set of differently aged vegetative stands and show that our method can be readily applied in the field with minimal effort.

\section{Methods}

We split our study into two parts: first, we determined if there is a link between $D$ and basal area per hectare (BA) as a proxy for quantifying forest canopy shape; and, second, we determined if there is a noticeable vegetation shape change during succession. First, we established five $400 \mathrm{~m}^{2}$ square plots in the SUNY Geneseo Roemer Arboretum (42 $\left.47^{\prime} 16^{\prime \prime} \mathrm{N}, 77^{\circ} 49^{\prime} 25^{\prime \prime} \mathrm{W}\right)$ and five $400 \mathrm{~m}^{2}$ square plots in the SUNY Geneseo/Genesee Valley Conservancy Research Reserve (42 $\left.49^{\prime} 59^{\prime \prime N}, 77^{\circ} 48^{\prime} 13^{\prime \prime} \mathrm{W}\right)$. Second, to address the relationship between $D$ and successional stage, we used three plots per stage, located in different areas of each of the above locations and an additional site along the southwest shore of nearby Hemlock Lake (approximately $42^{\circ} \mathrm{N} 68^{\prime} 19^{\prime \prime} \mathrm{N}, 77^{\circ} 60^{\prime} 95 " \mathrm{~W}$; Table 1). Plot sizes depended upon the tallest vegetation within an area to avoid plot sizes that would not capture the area studied; old field plots would have exaggeratedly low measurements of $D$ when measured in a plot of height $20 \mathrm{~m}$ (see Figure 2(a)). Therefore, we used $8000 \mathrm{~m}^{3}$ plots for old growth forests, $1000 \mathrm{~m}^{3}$ plots for young growth forests, $125 \mathrm{~m}^{3}$ plots for shrubby habitat, and $27 \mathrm{~m}^{3}$ plots for grassland.

\subsection{Forest Canopy Shape}

In each plot we calculated $D$ and total basal area per hectare (BA). To calculate $D$ for each plot we recorded x-y coordinates, diameter of the tree trunk at breast height (DBH; 1.37 m), height to lowest live branch (HLLB), and average canopy radius for each tree with a $\mathrm{DBH} \geq 5 \mathrm{~cm}$. We determined heights using a laser range finder to determine distance to the trunk and a clinometer to determine angles (see Figure 2). We categorized the shape of each tree canopy as ellipsoid, cylinder, or an upward or downward pointing cone. 


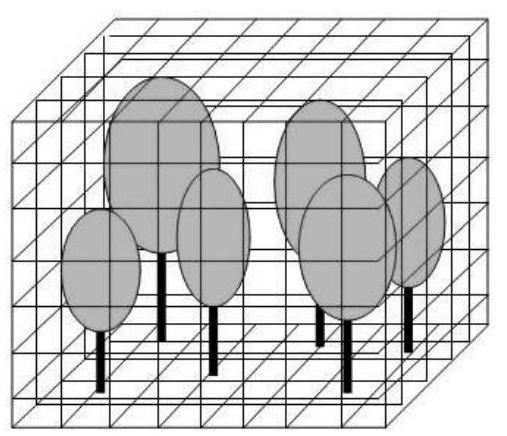

(a)

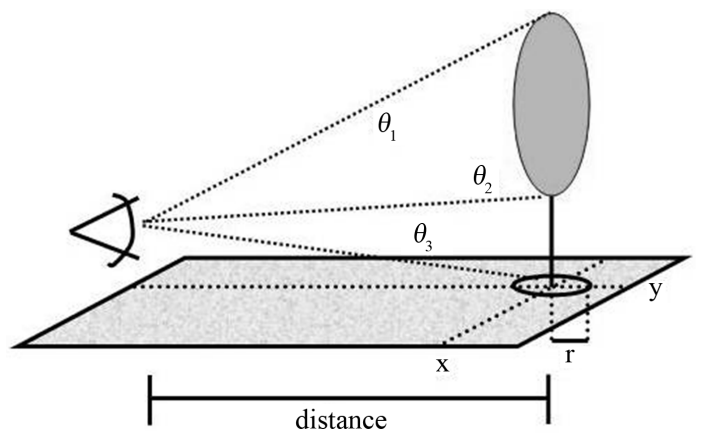

(b)

Figure 2. Field measurements required to estimate the fractal dimension $(D)$ of a forest plot. (a) Example of a sample forest plot broken down into small cubes. (b) Measurements of individual trees involve estimating distance to tree using a laser range finder and estimating angles to the bottom of the tree (theta 1), lowest live branch (theta 2), and top of the tree (theta 3 ). The average canopy radius is $r$. These measurements allow for the calculation of height to the lowest live branch and tree top. These data together allow for the reconstruction of forest canopies in a threedimensional matrix.

Table 1. Plot size at each sampling area based on the stage of sccession represented.

\begin{tabular}{|c|c|c|c|c|c|c|}
\hline \multirow{3}{*}{$\begin{array}{l}\text { Successional } \\
\text { Stage }\end{array}$} & \multicolumn{6}{|c|}{ Sampling area } \\
\hline & \multicolumn{2}{|c|}{ Roemer Arboretum } & \multicolumn{2}{|c|}{ Research Reserve } & \multicolumn{2}{|r|}{ Hemlock Lake } \\
\hline & Plots & Size $\left(\mathrm{m}^{2}\right)$ & Plots & Size $\left(m^{2}\right)$ & Plots & Size $\left(\mathrm{m}^{2}\right)$ \\
\hline Old Field & $2(\mathrm{~A}, \mathrm{~B})$ & (A)1.22 (B) 0.91 & 1 & 2.13 & 0 & N/A \\
\hline Shrubland & $2(\mathrm{~A}, \mathrm{~B})$ & (A) 1.52 (B) 2.13 & 1 & 1.83 & 0 & N/A \\
\hline Young Growth & 1 & 5.18 & $2(\mathrm{~A}, \mathrm{~B})$ & (A) 12.49 (B) 9.14 & 0 & N/A \\
\hline Old Growth & 0 & N/A & 0 & N/A & $3(\mathrm{~A}, \mathrm{~B}, \mathrm{C})$ & (A) 24.38 (B) 27.43 (C) 25.3 \\
\hline
\end{tabular}

$D$ was calculated for plots using the box-count method (see [45]). To employ this method, we developed a program, written in the C-programming language, that creates an 80 unit cubic matrix that pixilates each $20 \mathrm{~m} \times$ $20 \mathrm{~m}$ quadrat into $512,000\left(80^{3}\right)$ cells, each with dimension $0.25 \mathrm{~m}$ on a side. We placed values of " 1 " in cells that were intercepted by the tree canopy or trunk (otherwise cells were set to " 0 "). The program counts the number of " 1 's" for each box size, in increments that double the length of each side (i.e., sides of length 0.25 , $0.5,1,2,4,8$, and $16 \mathrm{~m}) . D$ is estimated by regressing the log of the number of boxes intercepted by trees against the log of the reciprocal of the length of one side of individual cells [45], see also [46]. The absolute value of the slope of this relationship is the estimate of $D$. This is a feasible approach due to the tight relationship between fractal dimension and power laws, and while it is a rigorous and well tested method, it has yet to be applied in this setting, to our knowledge [47].

The relationship between $D$ and $B A$ was assumed to fit the equation

$$
D=a\left(1-\mathrm{e}^{-b \cdot B A}\right),
$$

where $D$ is the fractal dimension, $a$ and $b$ are fitted coefficients, e is the base of natural logarithm, and $B A$ is the basal area. We use this two-parameter asymptotic function that assumes the relationship goes through the origin since a community without vegetation $(B A=0)$ would have a fractal dimension $D=0$. Flat sheets of continuous vegetation (e.g., a grassland measured at a large scale) would have $D$ approaching 2 , but since we are investigating the shape of tree canopies, the absence of trees would not have this estimate of shape. Since an object with $D=3$ represents a completely filled cube, the relationship was assumed to rise asymptotically with the constraint that $D \leq 3.0$. Interestingly, forests may have $D<2.0$ when their canopies contain relatively few trees with non-contiguous canopies. We fit this relationship using SPSS ver. 10.0 [48]. 
To assess the sensitivity of the method to the variability in the shape of individual tree crowns, we conducted randomization tests using one of the mature forest plots. Existing tree crown shapes were assigned randomly within each plot while all other tree parameters remained constant (i.e., the $\mathrm{x}$-y coordinates, HLLB, canopy radius, and tree height were not changed). Fifty canopies were created and $D$ estimated for each plot. We then created a forest with all ellipsoids, calculated $D$, and tested this against this distribution of $D$ 's in the randomized canopies using a one-sample t-test. This was then repeated for upward pointing crowns and cylinders. Normality tests for the distributions of $D$ were done using the Kolomogorov-Smirnov test.

\subsection{Vegetation Shape Change during Succession}

The plots in each location were used to estimate the $D$ and mean distance of the chronosequences (Table 1). Specific plots were chosen haphazardly with the intention of sampling representative forest patches. Young growth forest sites were predominated by trees with diameters less than $0.61 \mathrm{~m}$ (2 feet). While this does bring to light issues of a biased sample, it is necessary because an ordinal scale was used to rank the sites. The Western Finger Lakes region has been recovering from forest clearing from various agricultural uses.

We measured the height of the tallest plant in the chosen plot, x-y coordinates, HLLB and DBH (defined above), and the average canopy radius. We did not assign trees in plots with dense tree growth their own Euclidean shape for leafy areas because we could not readily determine the boundaries for each tree in this situation; rather, the whole area above the HLLB was treated as a solid. To account for gaps in these Euclidean approximations, each tree trunk was treated as a cylinder, filling space below the HLLB, and serving as a proxy for empty space above the HLLB.

To avoid the overly tedious work of finding coordinates of each blade of grass in grassland plots, an average height for the plot was taken as the grassland plots included here had patches that were noticeably taller than other patches. Shrubland plots had no HLLB and thus were given Euclidean shapes starting at ground level, with coordinates located at the center of the shrub. We used the program outlined above to calculate $D$ for each plot. For this investigation, however, we used a variation of this model to calculate the mean distance of each plot. The program calculated the average distance between all pairs of occupied cells (not merely the distance between points on the surface of different parts of the target object). That is, for each cell with a "1" (indicating the presence of a stem or branch), the program calculates the distance (in number of cells) to every other cell in the plot that has been assigned a value of " 1 ". Thus, our measure of mean distance serves as a reasonable estimate of the lacunarity of the plot. We preformed an analysis of variance on the outputs of the $D$ and mean distance assessments in R v. 2.15.0 [49].

\section{Results}

\subsection{Forest Canopy Shape}

Our results indicate that the complexity of the forest canopies, as estimated by $D$, increased asymptotically with the basal area of the forest plots $\left(D=2.2885 \times\left(1-\mathrm{e}^{-1.1173 B A}, \mathrm{r}^{2}=0.68\right)\right.$ with a $95 \%$ confidence interval about the asymptote (2.2885) of 0.135 (Figure 3). The $r^{2}$ values for the regressions used to determine $D$ exceeded 0.98 for all determinations of $D$.

Furthermore, the randomization tests revealed that, for this mixed-shaped forest canopy dominated by ellipsoids, changing to all ellipsoids did not significantly alter $D(t=1.64, \mathrm{df}=49, \mathrm{p}=0.11)$. Changing the canopy to all cones reduced $D$ significantly $(\mathrm{t}=57.5, \mathrm{df}=49, \mathrm{p}<0.001)$ while cylinders increased $D(\mathrm{t}=29.3, \mathrm{df}=49, \mathrm{p}<$ 0.001) (Figure 4). Overall, values for $D$ were highest when canopies were changed to cylinders, intermediate for ellipsoids, and lowest for cones. Distributions of $D$ were normal for each randomization test.

\subsection{Vegetation Shape Change during Succession}

Finally, we found no statistical difference between the average fractal dimensions of the vegetative areas representing discrete successional stages $(\mathrm{F}=0.213, \mathrm{df}=8,3, \mathrm{p}=0.8846$; Figure 5). The range of $D$ for each successional stage was 2.47-2.89 for grassland (mean $=2.68$, sd $=0.21$ ), 2.28-2.74 for shrub land (mean $=2.56$, sd $=0.24), 2.35-2.79$ for young growth forest (mean $=2.64$, sd $=0.25$ ), and $2.61-2.69$ for old growth forest (mean $=2.66$, sd $=0.05$ ). Furthermore, the mean distance (the shape filling property of the area) was not statistically different across the measured stages of succession, with the average mean distance value for all stages falling between 25 and 30 dimensionless units $(\mathrm{F}=1.3189, \mathrm{df}=8,3, \mathrm{p}=0.3341$; Figure 6). 


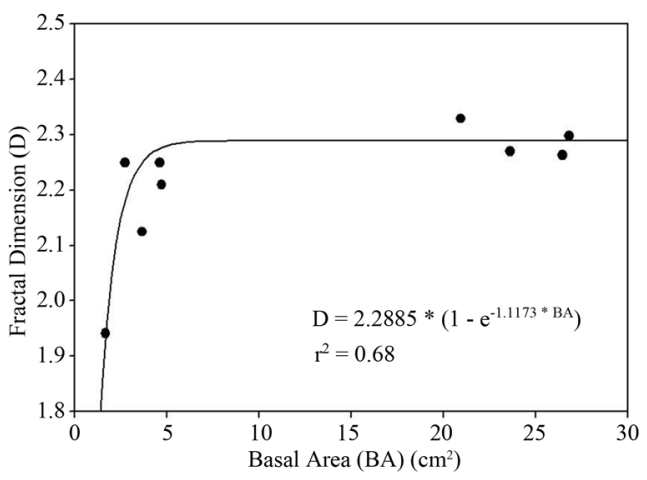

Figure 3. Relationship between fractal dimension and basal area of plots. The line was fit using nonlinear regression.

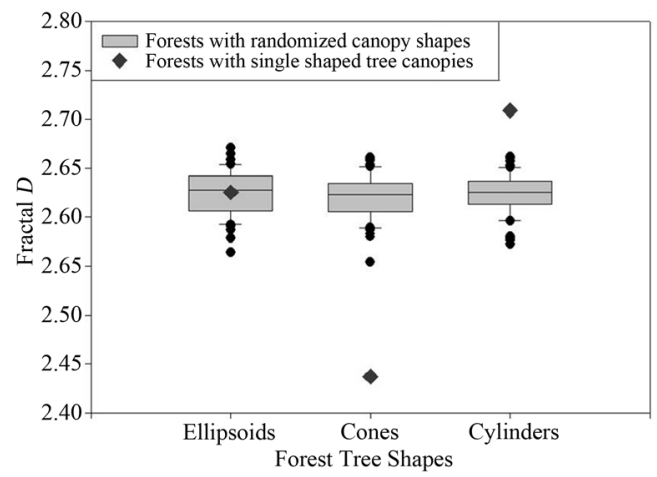

Figure 4. Results from the randomization test. Canopy shapes were chosen randomly and replaced existing trees. All other factors remained unchanged (e.g., x-y coordinates, height, etc.). Only the forest with canopies fixed to all ellipsoids was not significantly different (one-sample t-test) from the distribution of 50 randomizations of a forest plot with randomly selected canopy shapes. When canopies were fixed as cones and cylinders the estimate of D was signifcantly less than and greater than the randomized forest plots, respectively.

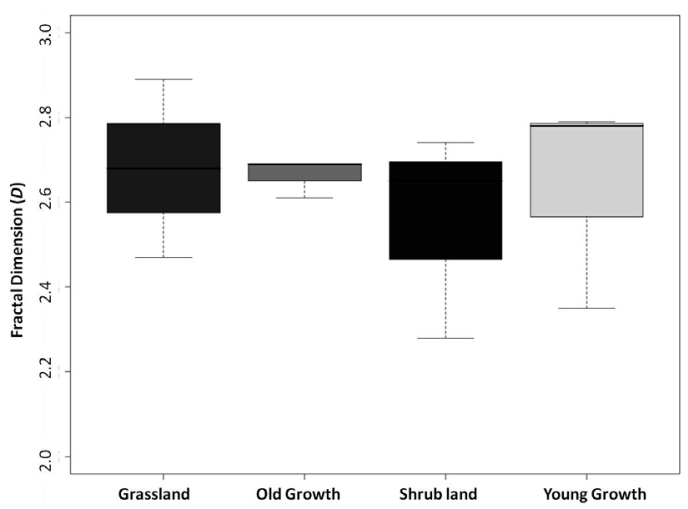

Figure 5. Fractal dimensions for each community type were not statistically different, suggesting conservation of overall shape, as quantified by the fractal dimension, during succession $(\mathrm{F}=0.213$, $\mathrm{df}=3,8, \mathrm{p}=0.8846)$. 


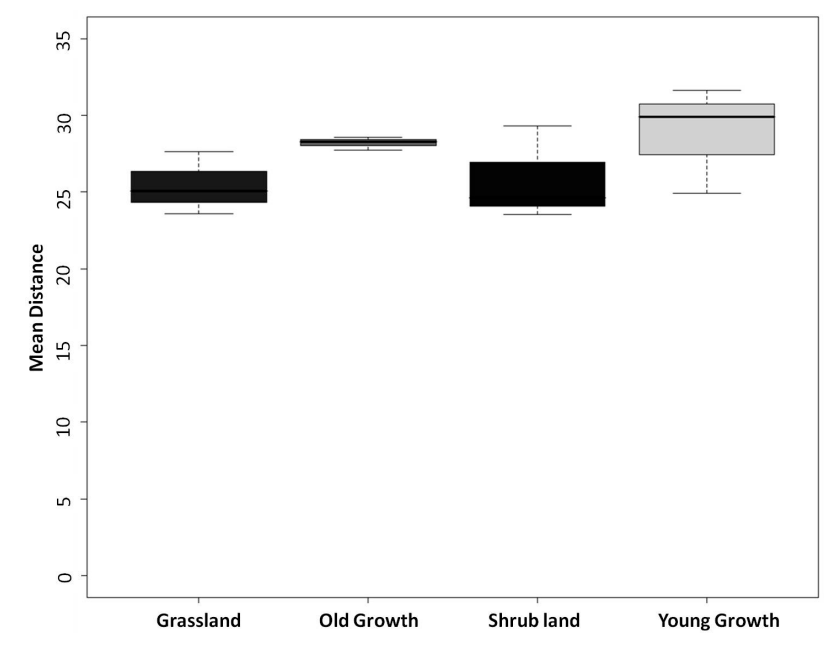

Figure 6. Mean distances for each community type were not statistically different, sugesting conservation of shape filling properties during succession $(\mathrm{F}=1.3189, \mathrm{df}=3,8, \mathrm{p}=0.3341)$.

\section{Discussion}

Although the structure of habitats has long been considered to have an important influence on niche availability, a direct quantification has been elusive [21]. The current work reports a simple technique that allows for the quantification of traditionally three-dimensional structures, such as forest canopies, using fractal geometry, as it has been developed for aquatic environments for over a decade [50]. We can estimate the structure of complex shapes using the box-count method to produce the fractal dimension for a variety of structures. The method described is relatively easy to implement and can be readily used to assess structural differences across systems; a tool that is sorely needed [7]. The $20 \mathrm{~m}^{2}$ plots each took between 30 minutes to an hour for one individual to complete. Teams of two researchers would be able to complete a dozen or more plots per day. This compares favorably against other techniques that are relatively tedious in their measurements [27]. We acknowledge, however, that we require further investigation to determine whether our method accurately estimates $D$ for these plots - and thus they are in fact equivalent—or if our method is incapable of detecting real differences.

Our results suggest that shape and structure are conserved properties of vegetative stands throughout the process of succession. It is important to note that although shape $(D)$ changes with $B A$, our results suggest that forest development is more complex than simply "trees are getting bigger". We have shown that gross morphology of the forest changes nonlinearly with $B A$. This change and the functional relationship between $B A$ and $D$ are likely to be important influences on species using the forest canopy (e.g., arthropods, or birds). The results from the randomization test suggest that switching canopies from the observed shapes to canopies with all cones or cylinders had a large statistical effect. This suggests that for these eastern deciduous forests the shape of individual trees influences the overall structure of the forest canopy, an effect that this method clearly detects.

Furthermore, combining the descriptive but insufficiently unique metric of $D$ with an estimate of the mean distance of points within an object yielded novel results about the spatial patterns of vegetative stands. We expected that stands at different stages of succession would exhibit significantly different measures of $D$ and mean distance; our results, however contradict this expectation on both fronts (at least, in the type of environment included in our study). First, similar values for $D$ values across successional stage may be attributable to genetic processes occurring at the individual level, as it has been shown to be heritable in trees [21]. Given the complex effects that tree architecture can have on animal communities, it would be important to investigate how D scales up from individual trees to whole forest stands. Our results from the investigation into the shape of forest canopies suggest that broad canopy shapes for individual trees may influence larger canopy architecture (see also [27]). Their work suggests that the structure of a single tree does scale up to describe the shape of the local neighborhood. Our method to efficiently calculate the fractal dimension of a vegetative stand may therefore be simplified even further; calculating $D$ for a single tree may be sufficient to assess the structure of the surrounding habitat through time. This has profound implications for forest and wildlife management given the strong connection between landscape genetics and landscape ecology [51]. 
In addition, the mean distance assessment showed no differences among the four stages of succession we considered here. This finding seemed counterintuitive as we anticipated that in the unlikely event that plots in different successional stages exhibited equivalent $D$, they would likely differ in the way they occupied the space, i.e., in their lacunarity. For instance, a purely grassy plot would tend to have a uniform height and consist of many stalks or blades of plants, while a mostly shrubby plot would consist of several bushes with extensive branching-more lateral structures than would be expected in a grassland and potentially greater distance between structures. This might then contribute to the expected differing degrees of animal species richness and diversity in plots displaying different stages of succession. Instead, we can exclude this feature as a possible cause and conclude that, while $D$ for a vegetative stand may not differ greatly during the course of succession, the functional $D$ may change. That is, the animals that interact with that vegetative stand may experience different aspects of its shape and structure and therefore preferentially move through and settle in one stand over another, a conclusion that has considerable support [2]-[5] [36]. For example, Bélisle and Desrochers [52] have shown that birds clearly avoid open grasslands when possible; yet smaller animals may spend most of their lives in such habitats.

The results we present here offer more encouraging signs that the use of fractal geometry in ecology can yield critical insights into natural phenomena and processes. We acknowledge, however, that our sample size is small, and our geographic focus is restricted. Our results are thus constrained and may be applied only to northeastern deciduous communities. Nevertheless, these results still may help forest managers manipulate canopy structures for certain canopy-dwelling species. Our results also indicate that selective logging could be accomplished to maintain (or alter, as necessary) the structure of a forest. How the shape of a forest canopy influences community properties, such as animal communities, plant species composition, and ecosystem services, remains an important research priority. The method we present here is useful for rapid assessment of community structure, relying on the determination of the fractal dimension $D$. It is our hope that the expanded use of this method will lead to a better understanding of the human-induced impact on the environment [53].

\section{Acknowledgements}

We thank C. Leary, D. Ruppe, S. Vrooman, H. Miller, N. Sprentall, and J. Varughese for assistance with this work, as well as helpful feedback on early versions of this manuscript.

\section{References}

[1] MacArthur, R. and MacArthur, J.W. (1961) On Bird Species Diversity. Ecology, 42, 594-598. http://dx.doi.org/10.2307/1932254

[2] Hixon, M.A. and Menge, B.A. (1991) Species Diversity: Prey Refuges Modify the Interactive Effects of Predation and Competition. Theoretical Population Biology, 39, 178-200. http://dx.doi.org/10.1016/0040-5809(91)90035-E

[3] Hull, S.L. (1997) Seasonal Changes in Diversity and Abundance of Ostracods on Four Species of Intertidal Algae with Differing Structural Complexity. Marine Ecology Progress Series, 161, 71-82. http://dx.doi.org/10.3354/meps161071

[4] Hauser, A., Attrill, M.J. and Cotton, P.A. (2006) Effects of Habitat Complexity on the Diversity and Abundance of Macrofauna Colonising Artificial Kelp Holdfasts. Marine Ecology Progress Series, 325, 93-100. http://dx.doi.org/10.3354/meps325093

[5] Dibble, E.D. and Thomaz, S.M. (2009) Use of Fractal Dimension to Assess Habitat Complexity and Its Influence on Dominant Invertebrates Inhabiting Tropical and Temperate Macrophytes. Journal of Freshwater Ecology, 24, 93-102. http://dx.doi.org/10.1080/02705060.2009.9664269

[6] Li, B.-L. (2000) Fractal Geometry Applications in Description of Patch Patterns and Patch Dynamics. Ecological Modelling, 132, 33-50. http://dx.doi.org/10.1016/S0304-3800(00)00303-3

[7] Kovalenko, K.E., Thomaz, S.M. and Warfe, D.M. (2012) Habitat Complexity: Approaches and Future Directions. Hydrobiologia, 685, 1-17. http://dx.doi.org/10.1007/s10750-011-0974-z

[8] Mandelbrot, B.B. (1983) The Fractal Geometry of Nature. Freeman, New York.

[9] Keller, J.M., Chen, S. and Crownover, R.M. (1989) Texture Description and Segmentation through Fractal Geometry. Computer Vision, Graphics and Image Processing, 45, 150-166. http://dx.doi.org/10.1016/0734-189X(89)90130-8

[10] Fielding, A. (1992) Applications of Fractal Geometry to Biology. Computer Applications in the Biosciences, 8, 359-366.

[11] Scheuring, I. and Reidi, R.H. (1994) Application of Multifractals to the Analysis of Vegetation Pattern. Journal of Vegetation Science, 5, 489-496. http://dx.doi.org/10.2307/3235975 
[12] Mandelbrot, B B. (1977) Fractals; Form, Chance and Dimension. Freeman, San Francisco.

[13] Voss, R.F. (1988) Fractals in Nature: From Characterization to Simulation. In: Peitgen, H.O. and Saupe, D., Eds., The Science of Fractal Images, Springer, New York, 21-70. http://dx.doi.org/10.1007/978-1-4612-3784-6_1

[14] O’Neill, R.V., Krummel, J.R., Gardner, R.H., Sugihara, G., Jackson, B., DeAngelis, D.L., Milne, B.T., Turner, M.G., Zygmunt, B., Christensen, S.W., Dale, V.H. and Graham, R.L. (1988) Indices of Landscape Pattern. Landscape Ecology, 1, 153-162. http://dx.doi.org/10.1007/BF00162741

[15] Kent, M., Gill, W.J., Weaver, R.E. and Armitage, R.P. (1997) Landscape and Plant Community Boundaries in Biogeography. Progress in Physical Geography, 21, 315-353. http://dx.doi.org/10.1177/030913339702100301

[16] Imre, A.R. and Bogaert, J. (2004) The Fractal Dimension as a Measure of the Quality of Habitats. Acta Biotheoretica, 52, 41-56. http://dx.doi.org/10.1023/B:ACBI.0000015911.56850.0f

[17] Wu, H.P. (1994) Allometrical Growth of the Quantitative Characters of Plants. I. Measurement of Leaf Size and Shape. Botanical Bulletin, 35, 115-124.

[18] Enquist, B.J., West, G.B., Charnov, E.L. and Brown, J.H. (1999) Allometric Scaling of Production and Life-History Variation in Vascular Plants. Nature, 401, 907-911. http://dx.doi.org/10.1038/44819

[19] West, G.B., Brown, J.H. and Enquist, B.J. (1999) The Fourth Dimension of Life: Fractal Geometry and Allometric Scaling of Organisms. Science, 284, 1677-1679. http://dx.doi.org/10.1126/science.284.5420.1677

[20] West, G.B., Brown, J.H. and Enquist, B.J. (1999) A General Model for the Structure and Allometry of Plant Vascular Systems. Nature, 400, 664-667. http://dx.doi.org/10.1038/23251

[21] Bailey, J.K., Bangert, R.K., Schweitzer, J.A., Trotter III, R.T., Shuster, S.M. and Whitham, T.G. (2004) Fractal Geometry Is Heritable in Trees. Evolution, 58, 2100-2102. http://dx.doi.org/10.1111/j.0014-3820.2004.tb00493.x

[22] Hastings, H.M. and Sugihara, G. (1993) Fractals: A User’s Guide for the Natural Sciences. Oxford University Press, New York.

[23] Alados, C.L., Pueyo, Y., Navas, D., Cabezudo, B., Gonzalez, A. and Freeman, D.C. (2005) Fractal Analysis of Plant Spatial Patterns: A Monitoring Tool for Vegetation Transition Shifts. Biodiversity and Conservation, 14, 1453-1468. http://dx.doi.org/10.1007/s10531-004-9669-3

[24] Lepš, J. (1988) Mathematical Modelling of Ecological Succession: A Review. Folia Geobotanica et Phytotaxonomica, 23, 79-94.

[25] Mladenoff, D.J., White, M.A., Pastor, J. and Crow, T.R. (1993) Comparing Spatial Pattern in Unaltered and Disturbed Forest Landscapes. Ecological Applications, 3, 294-306. http://dx.doi.org/10.2307/1941832

[26] Halley, J.M., Hartley, S., Kallimanis, A.S., Kunin, W.E., Lennon, J.J. and Sgardelis, S.P. (2004) Uses and Abuses of Fractal Methodology in Ecology. Ecology Letters, 7, 254-271. http://dx.doi.org/10.1111/j.1461-0248.2004.00568.x

[27] Bentley, L.P., Stegen, J.C., Savage, V.M., Smith, D.D., von Allmen, E.I., Sperry, J.S., Reich, P.B. and Enquist, B.J. (2013) An Empirical Assessment of Tree Branching Networks and Implications for Plant Allometric Scaling Models. Ecology Letters, 16, 1069-1078. http://dx.doi.org/10.1111/ele.12127

[28] MacArthur, R.H. and Horn, H.S. (1969) Foliage Profile by Vertical Measurements. Ecology, 50, 802-804. http://dx.doi.org/10.2307/1933693

[29] Aber, J.D. (1979) A Method for Estimating Foliage-Height Profiles in Broad-Leaved Forests. Journal of Ecology, 67, 35-40. http://dx.doi.org/10.2307/2259335

[30] Cramer, J., Fahey, T. and Battles, J. (2000) Patterns of Leaf Mass, Area and Nitrogen in Young Northern Hardwood Forests. American Midland Naturalist, 144, 253-264. http://dx.doi.org/10.1674/0003-0031(2000)144[0253:POLMAA]2.0.CO;2

[31] Shipley, B. and Lechowicz, M.J. (2000) The Functional Co-Ordination of Leaf Morphology, Nitrogen Concentration and Gas Exchange in 40 Wetland Species. EcoScience, 7, 183-194.

[32] Gower, S.T., Kucharik, C.J. and Norman, J.M. (1999) Direct and Indirect Estimation of Leaf Area Index, fAPAR and Net Primary Production of Terrestrial Ecosystems. Remote Sensing of Environment, 70, 29-51. http://dx.doi.org/10.1016/S0034-4257(99)00056-5

[33] Borkowski, W. (1999) Fractal Dimension Based Features Are Useful Descriptors of Leaf Complexity and Shape. Canadian Journal of Forest Restoration, 29, 1301-1310. http://dx.doi.org/10.1139/x99-112

[34] Monteiro, L.R., Borin, B. and de Reis, S.F. (2000) Shape Distance, Shape Spaces and the Comparison of Morphometric Methods. Trends in Ecology and Evolution, 15, 217-220. http://dx.doi.org/10.1016/S0169-5347(99)01775-9

[35] Byrne, M., Timmermans, M., Kidner, C. and Martienssen, R. (2001) Development of Leaf Shape. Current Opinion in Plant Biology, 4, 38-43. http://dx.doi.org/10.1016/S1369-5266(00)00133-3

[36] Morse, D.R., Lawton, J.H., Dodson, M.M. and Williamson, M.H. (1985) Fractal Dimension of Vegetation and the Dis- 
tribution of Arthropod Body Lengths. Nature, 314, 731-732. http://dx.doi.org/10.1038/314731a0

[37] Brokaw, N.V.L. (1982) The Definition of Treefall Gap and Its Effect on Measures of Forest Dynamics. Biotropica, 14, 158-160. http://dx.doi.org/10.2307/2387750

[38] Runkle, J.R. (1984) Development of Woody Vegetation in Treefall Gaps in a Beech-Sugar Maple Forest. Holarctic Ecology, 7, 157-164.

[39] Augspurger, C.K. and Franson, S.E. (1988) Input of Wind-Dispersed Seeds into Light-Gaps and Forest Sites in a Neotropical Forest. Journal of Tropical Ecology, 4, 239-252. http://dx.doi.org/10.1017/S0266467400002807

[40] Hubbell, S.P., Foster, R.B., O’Brien, S.T., Harms, D.E., Condit, R., Wechsler, B., Wright, S.J. and de Lao, S.L. (1999) Light-Gap Disturbances, Recruitment Limitation and Tree Diversity in a Neotropical Forest. Science, 283, 554-557. http://dx.doi.org/10.1126/science.283.5401.554

[41] Pickett, S.T.A. and White, P.S. (1985) The Ecology of Natural Disturbance and Patch Dynamics. Academic Press, Orlando.

[42] Collins, B.S. and Pickett, S.T.A. (1988) Response of Herb Layer Cover to Experimental Canopy Gaps. American Midland Naturalist, 119, 282-290. http://dx.doi.org/10.2307/2425811

[43] Bollinger, J., Sprott, J.C. and Mladenoff, D.J. (2003) Self-Organization Criticality and Complexity in Historical Landscape Patterns. Oikos, 100, 541-553. http://dx.doi.org/10.1034/j.1600-0706.2003.12109.x

[44] Dodson, M.M., Lawton, J.H., Morse, D.R. and Williamson, M.H. (1985) Fractal Dimension of Vegetation and the Distribution of Arthropod Body Lengths. Nature, 314, 731-733. http://dx.doi.org/10.1038/314731a0

[45] Peitgen, H.O., Jurgens, H. and Saupe, D. (1992) Fractals for the Classroom. Springer-Verlag, New York.

[46] Hartvigsen, G. (2000) The Analysis of Leaf Shape Using Fractal Geometry. The American Biology Teacher, 62, 664669. http://dx.doi.org/10.1662/0002-7685(2000)062[0664:TAOLSU]2.0.CO;2

[47] Brown, J.H., Gupta, V.K., Li, B., Milne, B.T., Restrepo, C. and West, G.B. (2002) The Fractal Nature of Nature: Power Laws, Ecological Complexity and Biodiversity. Philosophical Transactions of the Royal Society, London B, Biological Sciences, 357, 619-626. http://dx.doi.org/10.1098/rstb.2001.0993

[48] SPSS Inc. (2001) SPSS for Windows, Version 10.0. SPSS Inc., Chicago.

[49] R Development Core Team (2012) R: A Language and Environment for Statistical Computing. R Foundation for Statistical Computing, Vienna. http://www.R-project.org/

[50] Robson, B.J., Chester, E.T. and Barmuta, L.A. (2002) Using Fractal Geometry to Make Rapid Field Measurements of Riverbed Topography at Ecologically Useful Spatial Scales. Marine and Freshwater Research, 53, 999-1003. http://dx.doi.org/10.1071/MF01222

[51] Storfer, A., Murphy, M.A., Spear, S.F., Holderegger, R. and Waits, L.P. (2010) Landscape Genetics: Where Are We Now? Molecular Ecology, 19, 3496-3514. http://dx.doi.org/10.1111/j.1365-294X.2010.04691.X

[52] Bélisle, M. and Desrochers, A. (2002) Gap-Crossing Decisions by Forest Birds: An Empirical Basis for Parameterizing Spatially Explicit, Individual-Based Models. Landscape Ecology, 17, 219-231. http://dx.doi.org/10.1023/A:1020260326889

[53] Krummel, J.R., Gardener, R.H., Sugihara, G., O’Neill, R.V. and Coleman, P.R. (1987) Landscape Patterns in a Disturbed Environment. Oikos, 48, 321-324. http://dx.doi.org/10.2307/3565520 
Scientific Research Publishing (SCIRP) is one of the largest Open Access journal publishers. It is currently publishing more than 200 open access, online, peer-reviewed journals covering a wide range of academic disciplines. SCIRP serves the worldwide academic communities and contributes to the progress and application of science with its publication.

Other selected journals from SCIRP are listed as below. Submit your manuscript to us via either submit@scirp.org or Online Submission Portal.
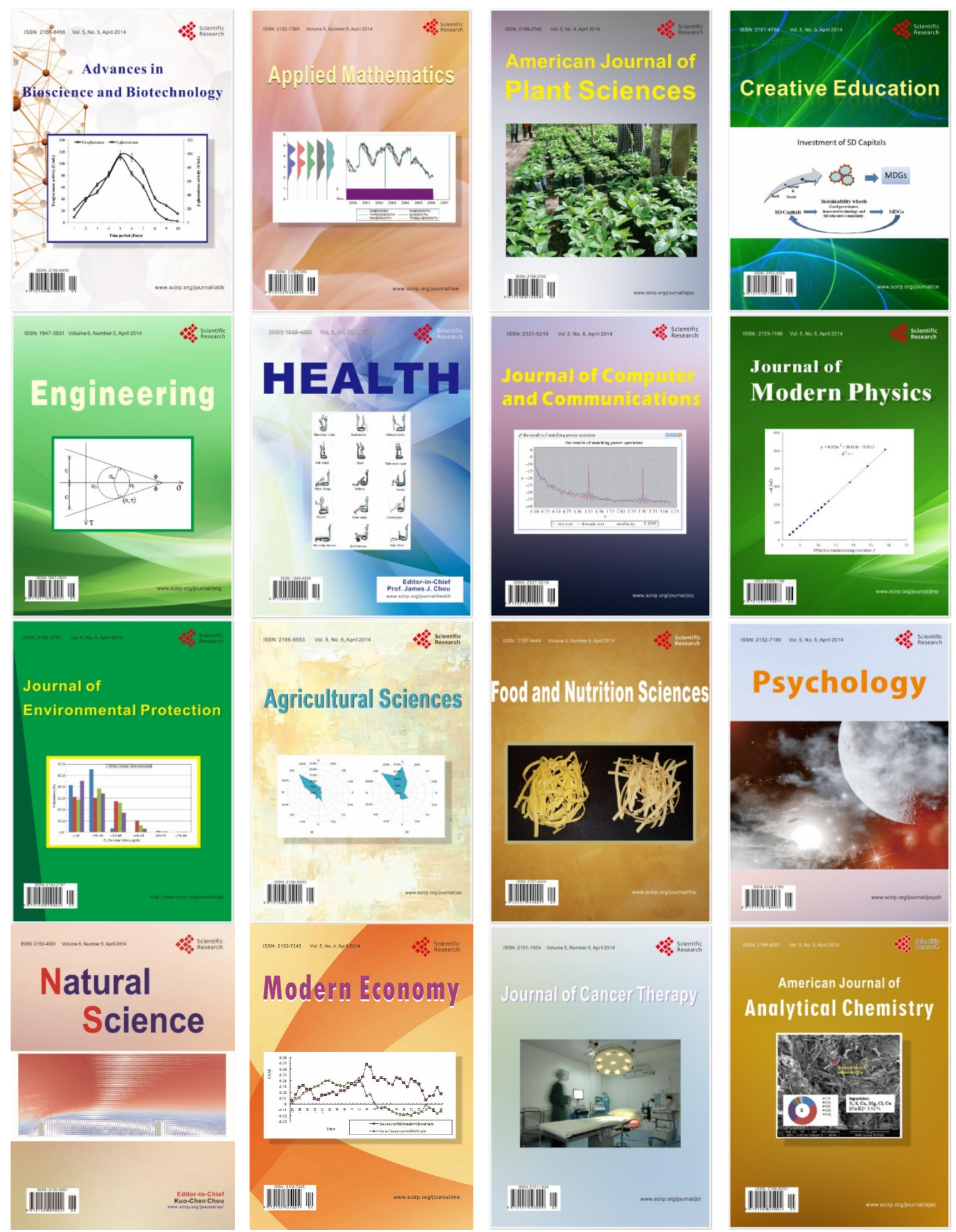